\title{
A Numerical Modelling Approach for Time-Dependent Deformation of Hot Forming Tools under the Creep-Fatigue Regime
}

\author{
B. Reggiani, L. Donati, and L. Tomesani \\ DIN Department, University of Bologna, Viale Risorgimento 2, 40136 Bologna, Italy \\ Correspondence should be addressed to B. Reggiani; barbara.reggiani4@unibo.it
}

Received 31 January 2016; Accepted 10 July 2016

Academic Editor: Jun Liu

Copyright (c) 2016 B. Reggiani et al. This is an open access article distributed under the Creative Commons Attribution License, which permits unrestricted use, distribution, and reproduction in any medium, provided the original work is properly cited.

\begin{abstract}
The present study was aimed at predicting the time-dependent deformation of tools used in hot forming applications subjected to the creep-fatigue regime. An excessive accumulated plastic deformation is configured as one of the three main causes of premature failure of tools in these critical applications and it is accumulated cycle by cycle without evident marks leading to noncompliant products. With the aim of predicting this accumulated deformation, a novel procedure was developed, presented, and applied to the extrusion process as an example. A time-hardening primary creep law was used and novel regression equations for the law's coefficients were developed to account not only for the induced stress-temperature state but also for the dwell-time value, which is determined by the selected set of process parameters and die design. The procedure was validated against experimental data both on a small-scale extrusion die at different stress, temperature, load states, and for different geometries and on an industrial extrusion die which was discarded due to the excessive plastic deformation after 64 cycles. A numerical-experimental good agreement was achieved.
\end{abstract}

\section{Introduction}

Forming processes like die-casting, extrusion, and forging are economical ways of producing large quantities of complex, tight tolerance parts in lightweight alloys such as aluminum and magnesium. However, these processes involve severe thermomechanical cyclic loads and high operating temperatures in a mixed creep and fatigue environment, leading to critical working conditions for molds and dies. In particular, the fatigue phenomenon appears since each process stroke represents a single working cycle, while creep arises, and can become dominant, with increasing temperatures and exposure times. In addition, the interaction of these yielding phenomena, that is, phenomena that progressively increase the level of accumulated plastic deformation in the component, can be more detrimental to die life than the single effect $[1,2]$. This translates into very strict demands on tool materials in terms of resistance against cyclic thermal and mechanical stresses, creep, and wear. Hot-work tool steels represent an optimal solution for manufacturing dies due to the high strength, also in hot conditions, good ductility, and also toughness [3]. However, cracking and failures for high-temperature forming tools are frequently documented in literature and in industrial practice. For example, a detailed analysis carried out on hot forging tools showed a strict correlation of failure modes with a various kind of influencing variables such as die material, die design, and die manufacturing and forging operations [4]. Kosec et al. divided the failure of dies for casting of aluminum into four main groups: big cracks, heat checking, cracking in corners, and sharp edges and abrupt transitions and cracking due to wear and erosion [5]. Arif and Sheikh presented an accurate investigation on the die failure mechanisms in hot aluminum extrusion concluding that, on an overall basis, all types of dies considered together, the failure modes were fracture (46\%), wear $(26 \%)$, detection (19\%), mixed mode (4\%), miscellaneous $(2 \%)$, and mandrel-related (3\%) [6-8]. Fracture and wear can be kept in some way under control by means of proper initial design and by reliable die heat treatment and/or coating [3]. In addition, both phenomena are marked by evident material discontinuities in terms of separation for fracture and displacement for wear. Conversely, an excessive 
inelastic deformation is a time-dependent, progressive, and irreversible phenomenon accumulated cycle by cycle that can lead to the going-out of the die's geometry and thus to its final discard even without the appearance of cracks or other material discontinuities [1,9]. A robust and reliable knowledge of these pieces of information is therefore recommended at the die design stage. This would indeed support engineers in predicting the maximum number of workable components in order to remain within the required tolerances and in estimating die durability.

At present, in industrial practice, die design is still mainly based on experience and a set of common shared rules $[10,11]$ while numerical simulations are seldom used. However, there are several disadvantages of this practice.

In-service experimental monitoring of time-dependent deformation, and then of stresses, requires complex setups due to the involved high temperatures and difficult tools' accessibility. Secondly, it merely allows for an ex-post evaluation since when noncompliant products are detected, expensive tools have been already manufactured and need to be discarded [12].

Conversely, numerical simulations have been already widely proved to be adequate tools to obtain reliable information on the level of stress and strain/deformation in the dies thus serving as "a priori" estimations for die design optimization and lifetime improvements. This has been demonstrated, as example, in $[13,14]$ for aluminum extrusion dies, in [15] for die-casting dies, and in [16] for the H11 tool steel widely used for forming tools. Indeed, the level of the achieved deformation is the first necessary input for evaluating the damage and the related lifetime models [16, 17]. Nowadays, manufacturing processes can be reliably analyzed in terms of plasticity conditions (strain, strain rates, and temperatures) but also pressure maps and damage distributions by means of finite element (FE) simulations. Moreover, dedicated structural codes allow more specific thermostructural analyses of molds and dies for the prediction of the stress and strain levels and distributions by offering a greater flexibility in terms of tool-material behavior models [13]. In this context, the most comprehensive elastoviscoplastic model based on the internal state variables has been developed by Chaboche within the continuum damage mechanism approach $[18,19]$. Despite its claimed ability to correctly describe most of the effects experimentally observed under creep-fatigue regime, the Chaboche deformation model is only partially available within the main commercial FE codes. In addition, no values of the coefficients are usually reported in technical papers, probably due to the time-consuming experimental calibration phase and, to the best of authors' knowledge, few validations of such models have been presented in literature against cases of industrial interest only on special tool steels. Indeed, the wide set of phenomena considered by the Chaboche model produces consequently a very wide number of parameters to be experimentally identified thus making the model almost inapplicable or extremely critical to be properly calibrated and implemented in FEM.

Accounting for all these restrictions, the authors proposed a simplified numerical modelling approach for predicting the time-dependent deformation of hot forming tools

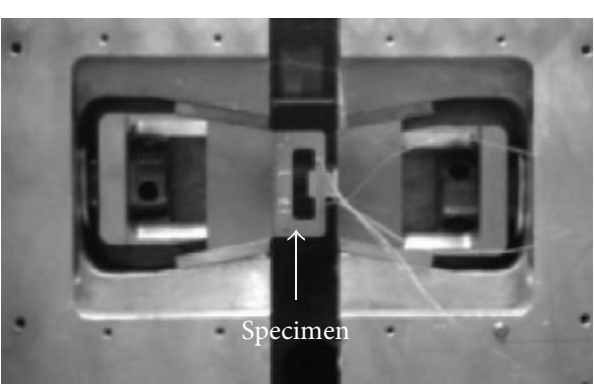

FIGURE 1: Specimen in the Gleeble simulator.

operating in the creep-fatigue regime with the main focus on time-dependent deformation of specimens rather than damage (material discontinuities in form of cracks, pores, or voids) mechanisms. The starting point was the application of a simple creep law for cyclic (fatigue) and cyclic with dwelltime (creep-fatigue) loads. Novel regression equations were developed for the creep coefficients to correlate with stress state, temperature, and exposure time.

With the aim of explaining in detail the procedure, it is applied to the specific case of extrusion dies. The considered die material is the H11 hot-work tool steel (X38CrMoV5-1), one of the most commonly used for forming applications [3]. The procedure was tested against an industrial die discarded due to an achieved excessive permanent deformation after 64 extruded billets. Experimental mandrel deflection was compared to numerical prediction.

\section{Materials and Method}

During metal forming (extrusion processing included) multiple billets are sequentially processed placing the die in the regime of fatigue, each billet representing a loading cycle. Accounting for the billet-die contact time during a single ram stroke and for the high temperature developed during the process, also the creep mechanism plays a significant role. So that the die deformation mechanism is due to creep-fatigue interaction $[2,20]$.

An innovative physical experiment was proposed by the authors reproducing the thermomechanical conditions of an extrusion die [21]: the specimens resembled the mandrel of a porthole die on a small scale, thus accounting for realistic stress-strain distribution and surface conditions, and were made of H11 (X38CrMoV5-1) hot-work tool steel. The experimental tests were performed on a Gleeble simulator by heating the specimen using Joule's effect and by applying a full compressive load to the specimen up to 6.1 hours or till specimen failure (Figure 1).

The experimental trials included four levels of temperature, namely, $380^{\circ} \mathrm{C}, 490^{\circ} \mathrm{C}, 540^{\circ} \mathrm{C}$, and $580^{\circ} \mathrm{C}$, and three levels of average stresses of 400,600 , and $800 \mathrm{MPa}$ in the bridges of the specimen. A number of porthole dies were preliminary simulated to properly calibrate the load level in order to generate in the specimen's bridges the same average stress as in the dies' ones (Figure 2(h)). Also, the testing temperature was that of the bridges and mandrel as measured by 15 thermocouples placed in the specimen during the experiments [21]. Three types of load were applied: pure creep 


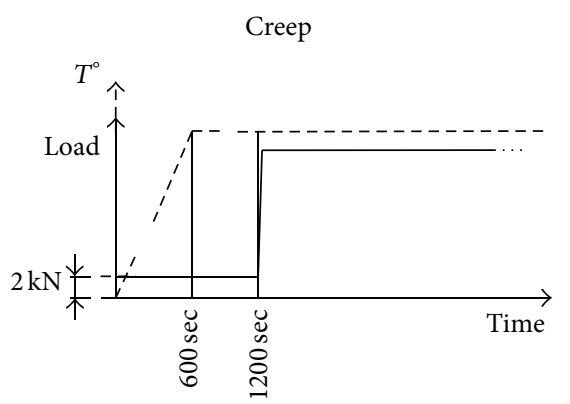

(a)

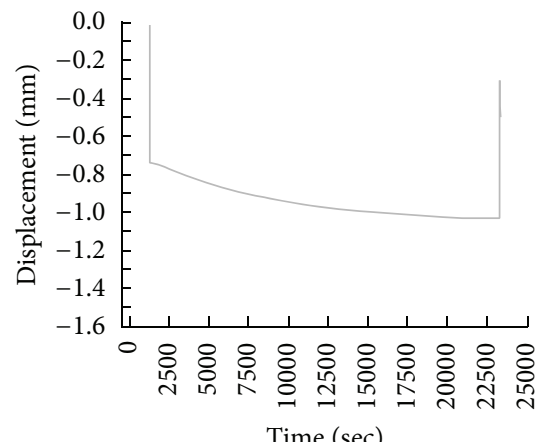

(d)

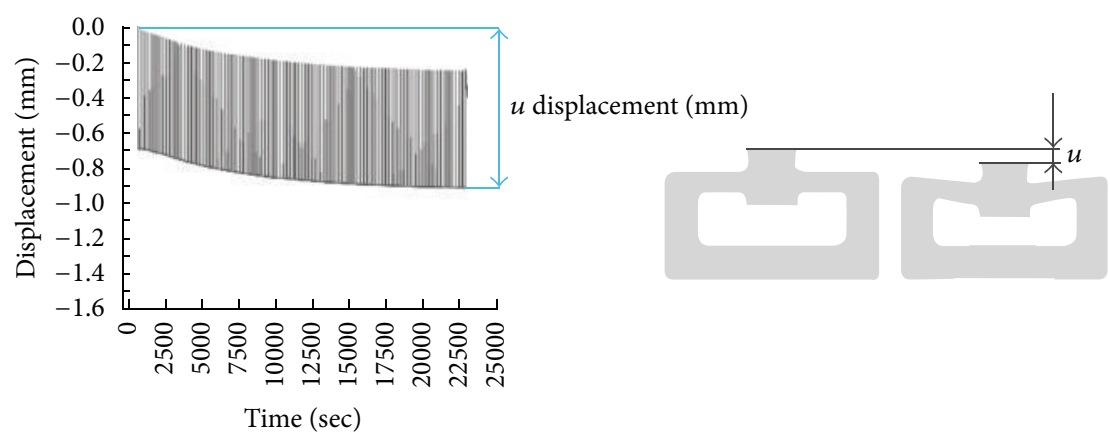

(g)

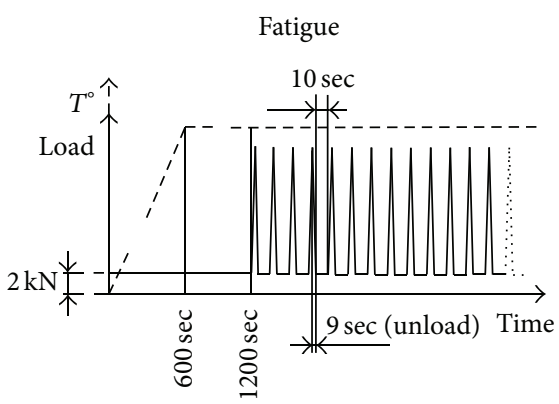

(b)

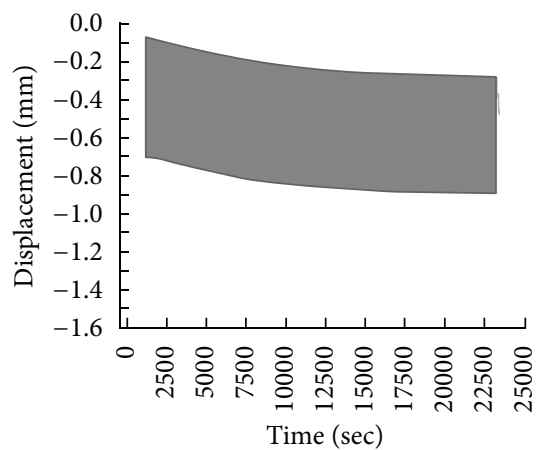

(e)

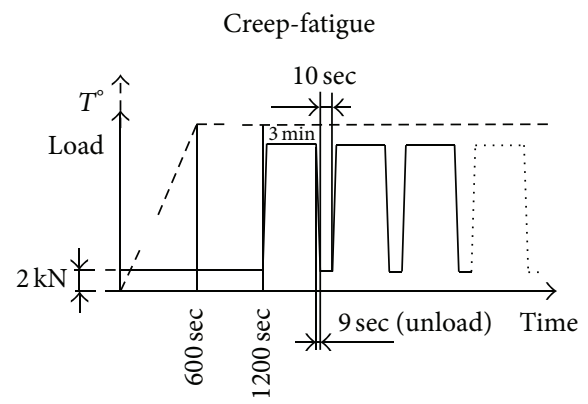

(c)

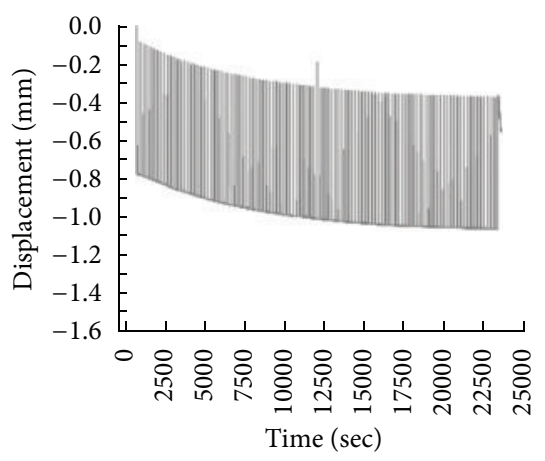

(f)

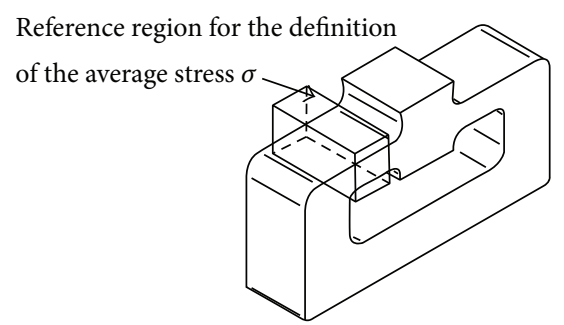

(h)

Figure 2: $(a, b, c)$ Waveform of the applied load and $(d, e, f)$ output peak displacement over the testing time for the three loading conditions at $600 \mathrm{MPa}$ and $490^{\circ} \mathrm{C}$ (data not purged by the press deformation). (g) Schematic explanation of the results. (h) Reference region for the definition of the average stress in the small-scale die specimen.

(with the load held at a fixed value), fatigue (cyclic load), and creep-fatigue (cyclic load with 3 minutes of dwell time) (Figures 2(a), 2(b), and 2(c)). Creep-fatigue represents the testing condition with a prescribed dwell or exposure time; creep and fatigue tests correspond to two extreme conditions of simulating, respectively, an infinite and a zero dwell-time. In case of extrusion, the dwell time is a function of the billet length, ram speed, and extrusion ratio, and it increases with the raising of the billet length and extrusion ratio and with the decreasing of the ram speed. As main output of the test, the displacement of the specimens' mandrel $(u)$, as caused by the specific loading conditions (load type, temperature, and stress level), was recorded over the testing time (Figure 2(g)). Specifically, the pure creep load generated a continuous curve (Figure 2(d)) while the pure fatigue and the creep-fatigue loads generated a cyclic curve with the loading-unloading displacement's path corresponding to each cycle (Figures 2(e) and 2(f)).
As observed for standard tests for the same steel [22], a comparable pattern of the mandrel displacement-time curve was found for all the experimental conditions reproducing the stages of softening typical of the strain evolution in a standard creep test. In particular, the specific ranges of investigated temperatures and stresses pointed out a primary phase without saturation typical of the secondary creep. Thus, an exponential type law was chosen to predict the displacement of the mandrel over time accounting for the stress, time, and temperature behavior dependency of the material response in this region of deformation, that is, the time-hardening creep law [23]; consider the following:

$$
\dot{\varepsilon}=C_{1} \cdot \sigma^{C_{2}} \cdot T^{C_{3}},
$$

in which $\dot{\varepsilon}$ is the strain rate, $\sigma$ and $T$ are the stress and temperature levels, and $C_{1}, C_{2}$, and $C_{3}$ are material constants. 
TABLE 1: The computed values of time-hardening law coefficients.

\begin{tabular}{lccccr}
\hline & $n$ & $m$ & $a_{0}$ & $C_{1}$ & $C_{2}$ \\
\hline$T^{\circ}=450$ & 3,50493 & 0,0675 & $1,0858 E-12$ & $7,329 E-14$ & 3,5049 \\
$T^{\circ}=500$ & 1,85103 & 0,085 & $1,6965 E-07$ & $1,442 E-08$ & 1,8510 \\
$T^{\circ}=550$ & 1,4848 & 0,10625 & $4,198 E-06$ & $4,460 E-07$ & $-0,9325$ \\
\hline
\end{tabular}

However, other primary creep equations could have been selected also adding the contribution of the secondary phase in case of specimen's softening saturation.

For a better estimation, initial values of the coefficients for (1) and the H11 tool steel were extracted from data taken in literature for pure creep tests at different stress and temperature levels $[24,25]$ according to the following procedure:

(1) Time-hardening law expressed in terms of creep strain:

$$
\varepsilon=a_{0} \sigma^{n} t^{m}
$$

where $\varepsilon$ is the strain, $\sigma$ is the stress level, $t$ is the time of the load application, and $a_{0}, n$, and $m$ are material constants.

(2) Passage to the logarithmic form:

$$
\begin{aligned}
\ln (\varepsilon) & =\ln \left(a_{0}\right)+n \ln (\sigma)+m \ln (t) \\
& =a_{1}+n \ln (\sigma)+m \ln (t) .
\end{aligned}
$$

(3) For each level of temperature, $n$ computed by averaging values for fixed times $(\ln (t)$ constant) and variable stresses:

$$
\ln (\varepsilon)=\ln \left(a_{0}\right)+n \ln (\sigma)+m \ln (t)=a_{2}+n \ln (\sigma)
$$

(4) For each level of temperature, $m$ computed by averaging values for fixed stresses $(\ln (\sigma)$ constant) and variable times:

$\ln (\varepsilon)=\ln \left(a_{0}\right)+n \ln (\sigma)+m \ln (t)=a_{3}+m \ln (t)$.

(5) For each level of temperature, $a_{0}$ computed by entering $n$ and $m$ in (1) for fixed times and by averaging the values:

$$
\ln (\varepsilon)-n \ln (\sigma)-m \ln (t)=\ln \left(a_{0}\right) .
$$

(6) Computation of the coefficients in (1):

$$
\begin{aligned}
\dot{\varepsilon}=\frac{d \varepsilon}{d t}=a_{0} \cdot m \cdot \sigma^{n} \cdot t^{m-1}=C_{1} \cdot \sigma^{C_{2}} \cdot T^{C_{3}} \\
C_{1}=a_{0} \cdot m, C_{2}=n, C_{3}=m-1 .
\end{aligned}
$$

The resulting values of the coefficients are reported in Table 1 based on the experimental data in $[24,25]$.

By means of FE analyses, the values reported in Table 1 were optimized for the set of experimental tests performed on the small-scale mandrel specimens [21]. The temperature distribution in the specimen was computed by performing a thermal-electrical simulation [26]. While the time-hardening law in (1) is usually applied in case of creep results for which continuous curves are generated (Figures 2(a) and 2(d)), its application for the fatigue (Figures 2(b) and 2(e)) and creepfatigue (Figures 2(c) and 2(f)) tests is a nonconventional use since loading-unloading ramps of the cycles are not modelled. So, for these tests, a continuous curve was extrapolated by connecting the peak values of the displacement of each cycle and applying the same approach as for the creep tests (Figure 3). In Table 2, the values of the optimized coefficients $C_{1}, C_{2}$, and $C_{3}$ are reported.

Figure 4 graphically shows the numerical correlations expressed in Table 2.

It emerges that $C_{1}$ is a function of the temperature level and of the dwell time (type of applied load) while it is independent of the stress level. The coefficient $C_{3}$ can be considered to be dependent only on the selected temperature level while $C_{2}$, also if not so marked, is a function of all the involved parameters, that is, the stress and temperature levels and the dwell time; indeed, even very small variations of this parameter were found to have a great influence on the output results in terms of predicted numerical displacement of the specimen. Novel empirical regressions were formulated in order to correlate each coefficient of the time-hardening creep law to the stress-temperature-load state as follows:

$$
\begin{aligned}
& C_{1}=\left(C_{1 \min } \cdot\left[\left(\frac{C_{1 \max }}{C_{1 \min }}-1\right) \cdot\left(\frac{T}{T_{\max }}\right)^{\left(K_{1} / T\right)}\right]\right) \cdot Q \cdot t_{\text {dwell }}^{R} \\
& C_{1 \min }=C_{1}\left(T_{\text {min,creep-fatigue }}\right), C_{1 \max }=C_{1}\left(T_{\text {max,creep-fatigue }}\right), K_{1}, Q, R=\text { material costants, } \\
& C_{2}=\left(E \cdot \sigma^{F} \cdot T^{G}\right) \cdot N \cdot t_{\mathrm{dwell}}^{U} E, F, G, N, U=\text { material costants, } \\
& C_{3}=-\left(\left|C_{3 \min }\right| \cdot\left[1+\left(\left|\frac{C_{3 \max }}{C_{3 \min }}\right|-1\right) \cdot\left(\frac{T}{T_{\max }}\right)^{\left(K_{3} / T\right)}\right]\right) \\
& C_{3 \min }=C_{3}\left(T_{\text {min,creep-fatigue }}\right), C_{3 \max }=C_{3}\left(T_{\text {max,creep-fatigue }}\right), K_{3}=\text { material costants. }
\end{aligned}
$$




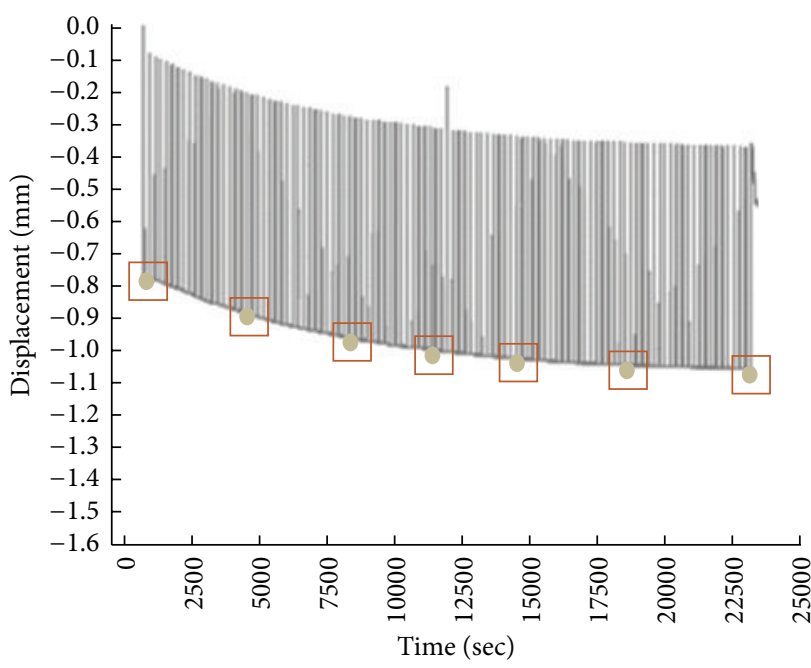

(a)

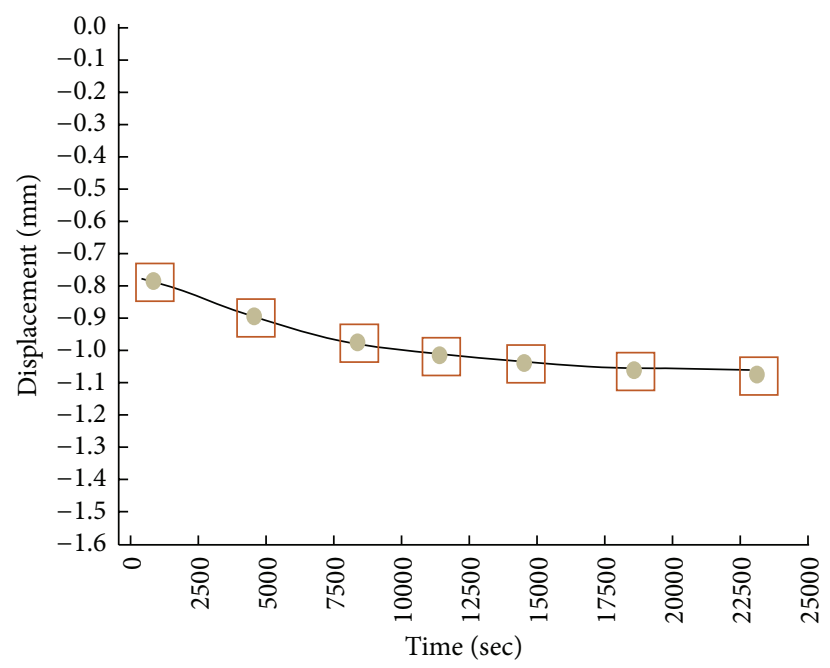

(b)

Figure 3: (a) Original rough experimental cyclic creep-fatigue curve (loading-unloading path of each cycle is reported) and (b) the extrapolated continuous curve; dots are example of the extracting points.

Fatigue (0 dwell time)
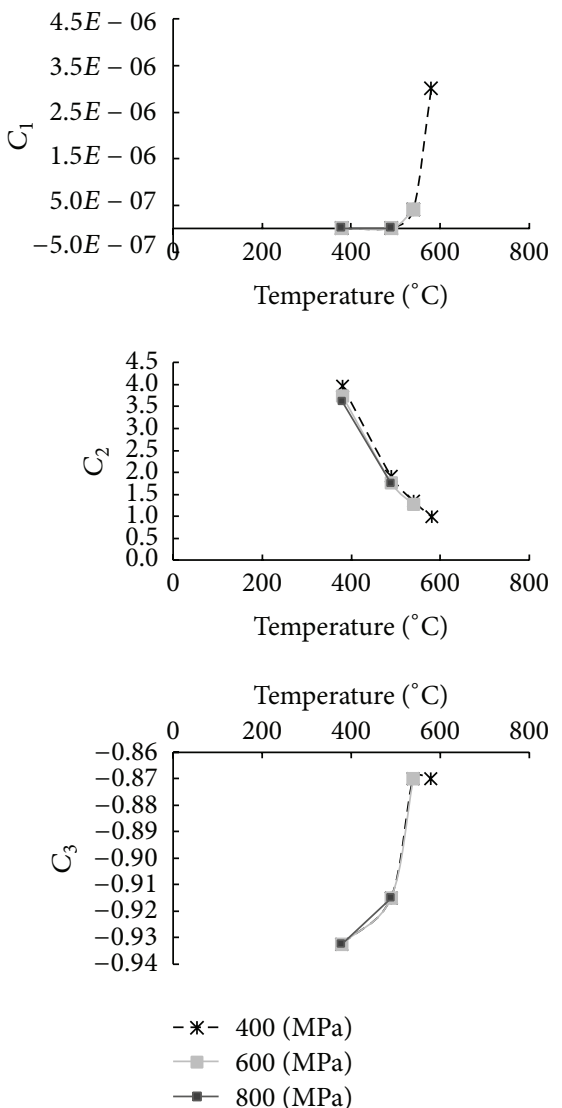

Creep (infinite dwell time)
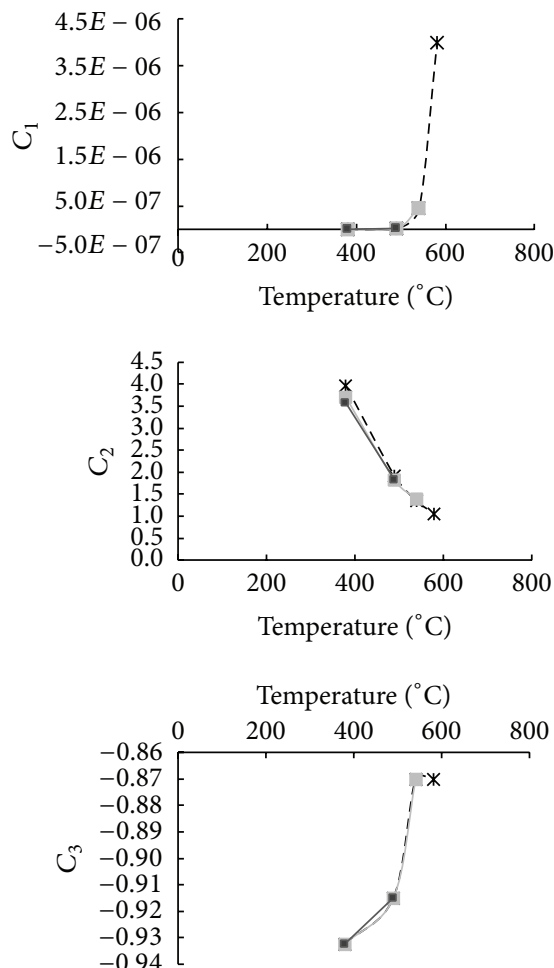

Creep-fatigue (3 min dwell time)
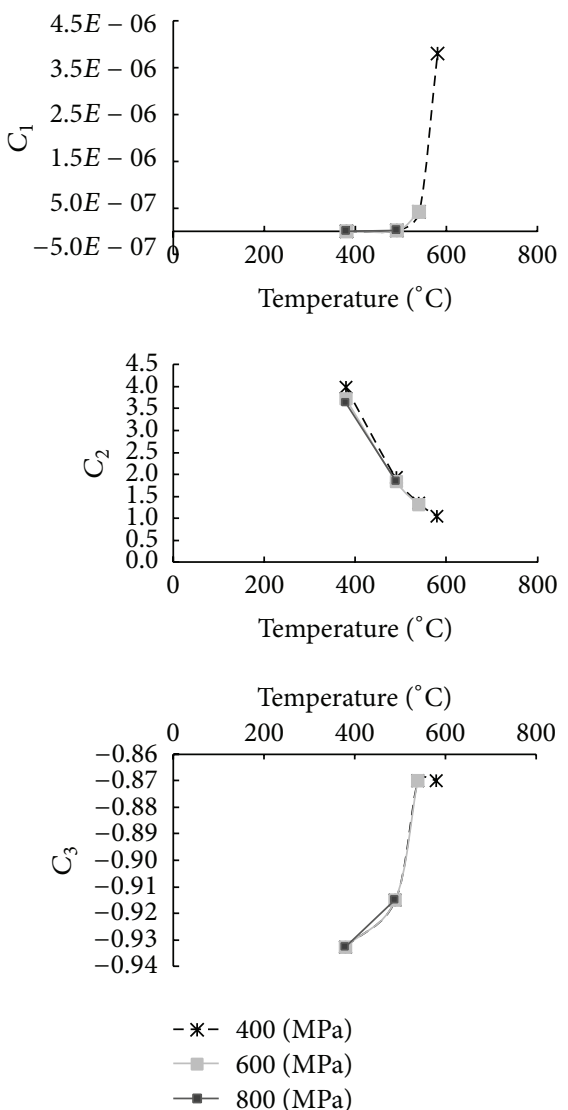

FIGURE 4: Coefficients of (1) (on $y$-axis) reported as function of the temperature (on $x$-axis) for each loading condition (in column) and stress level (different type of curves). 
TABLE 2: Optimized values of the coefficients in (1) on the basis of experimental data for creep, fatigue, and creep-fatigue conditions.

(a)

\begin{tabular}{rcccc}
\hline \multicolumn{5}{c}{ Creep } \\
& $380\left[{ }^{\circ} \mathrm{C}\right]$ & $490\left[{ }^{\circ} \mathrm{C}\right]$ & $540\left[{ }^{\circ} \mathrm{C}\right]$ & $580\left[{ }^{\circ} \mathrm{C}\right]$ \\
\hline$C_{1}$ & & & \\
$400[\mathrm{MPa}]$ & $7.00 E-14$ & $1.44 E-08$ & $4.46 E-07$ & $4.00 E-06$ \\
$600[\mathrm{MPa}]$ & $7.33 E-14$ & $1.44 E-08$ & $4.46 E-07$ & \\
$800[\mathrm{MPa}]$ & $7.33 E-14$ & $1.44 E-08$ & & \\
\hline$C_{2}$ & & & & \\
$400[\mathrm{MPa}]$ & 3.97 & 1.92 & 1.35 & \\
$600[\mathrm{MPa}]$ & 3.70 & 1.82 & 1.40 & \\
$800[\mathrm{MPa}]$ & 3.57 & 1.82 & & \\
\hline$C_{3}$ & & & & \\
$400[\mathrm{MPa}]$ & -0.9325 & -0.9150 & -0.8700 & \\
$600[\mathrm{MPa}]$ & -0.9325 & -0.9150 & -0.8700 & \\
$800[\mathrm{MPa}]$ & -0.9325 & -0.9150 & & \\
\hline
\end{tabular}

(b)

\begin{tabular}{lcccc}
\hline \multicolumn{5}{c}{ Fatigue } \\
& $380\left[{ }^{\circ} \mathrm{C}\right]$ & $490\left[{ }^{\circ} \mathrm{C}\right]$ & $540\left[{ }^{\circ} \mathrm{C}\right]$ & $580\left[{ }^{\circ} \mathrm{C}\right]$ \\
\hline$C_{1}$ & & & & \\
$400[\mathrm{MPa}]$ & $6.00 E-14$ & $1.33 E-8$ & $4.00 E-7$ & $3.00 E-06$ \\
$600[\mathrm{MPa}]$ & $6.00 E-14$ & $1.33 E-8$ & $4.00 E-7$ & \\
$800[\mathrm{MPa}]$ & $6.00 E-14$ & $1.33 E-8$ & & \\
\hline$C_{2}$ & & & & \\
$400[\mathrm{MPa}]$ & 3.96 & 1.90 & 1.34 & \\
$600[\mathrm{MPa}]$ & 3.74 & 1.77 & 1.27 & \\
$800[\mathrm{MPa}]$ & 3.60 & 1.74 & & -0.8700 \\
\hline$C_{3}$ & & & & \\
$400[\mathrm{MPa}]$ & -0.9325 & -0.9150 & -0.8700 & \\
$600[\mathrm{MPa}]$ & -0.9325 & -0.9150 & -0.8700 & \\
$800[\mathrm{MPa}]$ & -0.9325 & -0.9150 & &
\end{tabular}

(c)

\begin{tabular}{|c|c|c|c|c|}
\hline \multicolumn{5}{|c|}{ Creep-fatigue } \\
\hline & $380\left[{ }^{\circ} \mathrm{C}\right]$ & $490\left[{ }^{\circ} \mathrm{C}\right]$ & $540\left[{ }^{\circ} \mathrm{C}\right]$ & $580\left[{ }^{\circ} \mathrm{C}\right]$ \\
\hline \multicolumn{5}{|l|}{$C_{1}$} \\
\hline $400[\mathrm{MPa}]$ & $6.40 E-14$ & $1.42 E-8$ & $4.20 E-7$ & $3.80 E-06$ \\
\hline $600[\mathrm{MPa}]$ & $6.40 E-14$ & $1.42 E-8$ & $4.20 E-7$ & \\
\hline $800[\mathrm{MPa}]$ & $6.40 E-14$ & $1.42 E-8$ & & \\
\hline \multicolumn{5}{|l|}{$C_{2}$} \\
\hline $400[\mathrm{MPa}]$ & 3.97 & 1.92 & 1.35 & 1.05 \\
\hline $600[\mathrm{MPa}]$ & 3.72 & 1.84 & 1.30 & \\
\hline $800[\mathrm{MPa}]$ & 3.62 & 1.83 & & \\
\hline \multicolumn{5}{|l|}{$C_{3}$} \\
\hline $400[\mathrm{MPa}]$ & -0.9325 & -0.9150 & -0.8700 & -0.8700 \\
\hline $600[\mathrm{MPa}]$ & -0.9325 & -0.9150 & -0.8700 & \\
\hline $800[\mathrm{MPa}]$ & -0.9325 & -0.9150 & & \\
\hline
\end{tabular}

In (8), $t_{\text {dwell }}$ is the time in which, during a creep-fatigue test, the imposed load is kept constant and, as previously observed, for the specific case of extrusion dies, it is correlated to the
TABLE 3: Material constants used in (8) for the H11 tool steel.

\begin{tabular}{lclccc}
\hline & $C_{1}$ & & $C_{2}$ & \multicolumn{2}{c}{$C_{3}$} \\
\hline$C_{1 \max }$ & $3.8 E-06$ & $E$ & $1.30 E+08$ & $C_{3 \max }$ & -0.87 \\
$C_{1 \min }$ & $6.4 E-06$ & $F$ & -0.11245 & $C_{3 \min }$ & -0.9325 \\
$K_{1}$ & 16650 & $G$ & -2.8021 & $K_{3}$ & 3000 \\
$Q$ & 1.0421 & $N$ & 1.00251 & & \\
$R$ & 0.0124698 & $U$ & 0.002025 & & \\
\hline
\end{tabular}

billet length, ram speed, and extrusion ratio. Instead, $C_{1 \max }$, $C_{1 \text { min }}$ and $C_{3 \max }, C_{3 \min }$ represent the values of the coefficients found for the maximum and minimum temperatures in the selected range of experimental investigation in case of creepfatigue load for the first and the third coefficients. Parameters $K_{1}, Q, R, E, F, G, N, U$, and $K_{3}$ are material constants. For the presented specific case of H11 tool steel, the coefficient and the material constants in (8) are summarized in Table 3.

The selected equations, among different ones tested, were those best fitting the set of experimental data. A total of 36 experimental tests were initially performed to verify the sensibility of the small-scale die specimen to the operational conditions (4 levels of stress and temperature and three loading schemes) and the results were used to calibrate the model. However, the selected equations form allows reducing the number for a perfect matching to 27 (three levels of stress, temperature, and loading type) that, for a rougher estimation, can be additionally reduced to 12 (two levels of stress, temperature, and three loading types). The contribution of the dwelltime parameters $\left(Q, R, N, U\right.$, and $\left.t_{\text {dwell }}\right)$ was kept separated in order to further limit the number of experimental tests to calibrate the equations' coefficients for the cases in which a fixed dwell time can be considered ( 9 for a perfect matching and 4 for a rougher estimation).

The set of (8) was then implemented in a dedicated APDL subroutine in the ANSYS Inc. code and run to get an element-by-element assessment of the coefficients as a function of the specific $(\sigma, T)$ state and, additionally, of the specific workpiece-die contact (dwell) time.

In a first verification stage, the proposed procedure was validated against additional experimental data performed with different specimen geometries, not included in the optimization step of the coefficients. After that, the procedure was tested by comparing numerical predictions of the mandrel displacement history with experimental data for an industrial extrusion die.

\section{Results and Discussion}

Results of the calibration phase of the model are reported in Figure 5 for each level of tested stress and temperature for the creep loading configuration. For these conditions, the dwell time was imposed equal to 6.1 hours. In Figure 6, a magnification of the typical comparison output that shows the peak mandrel displacement along the load direction is reported as experimentally computed and numerically predicted over the total testing time. The average percentage error over all the simulated creep conditions was $12.7 \%$ corresponding to $0.06 \mathrm{~mm}$ difference. The applied methodology fits an 

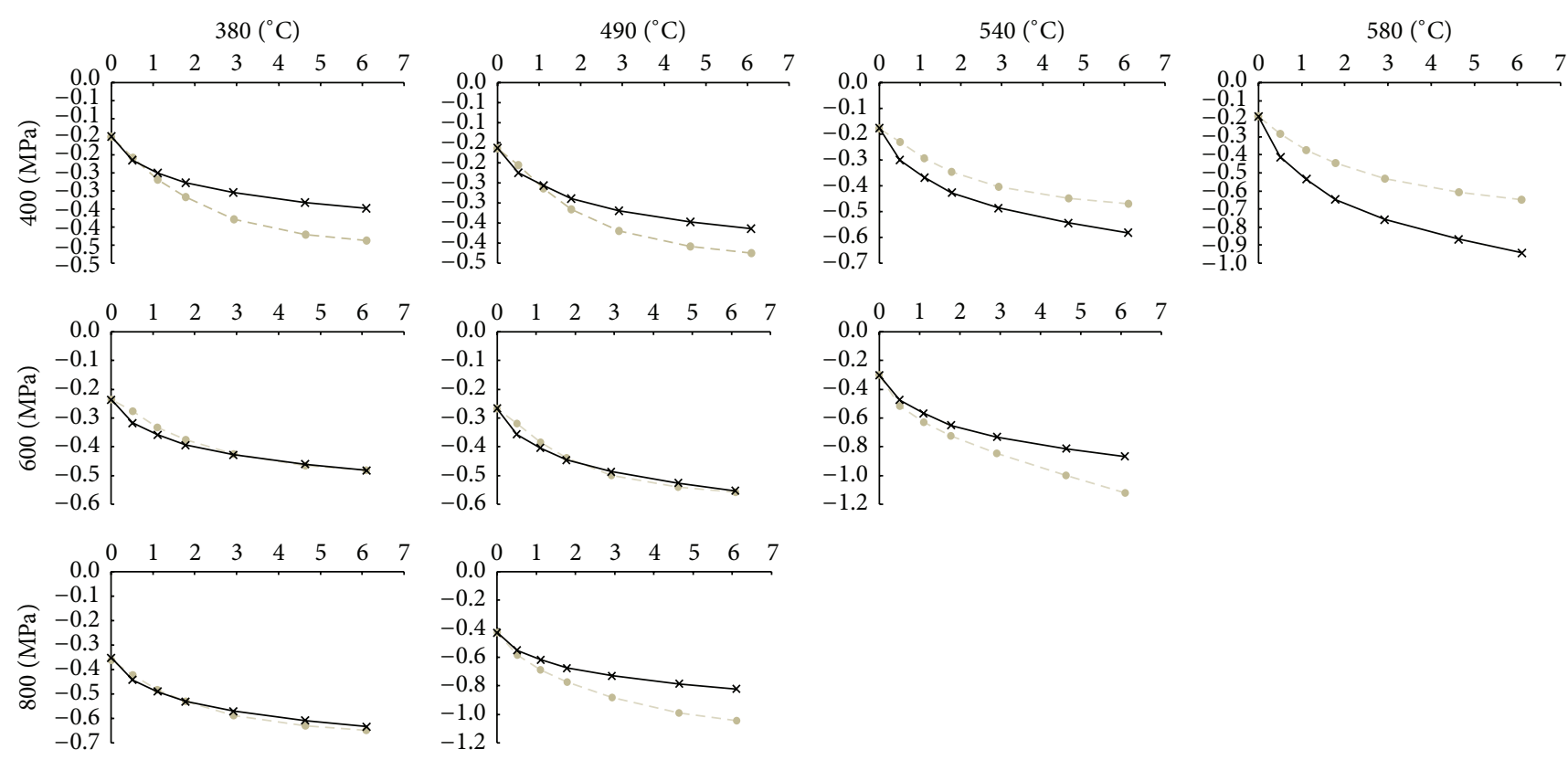

- Experimental
$\rightarrow$ Numerical

FIGURE 5: Experimental versus numerical displacement of the mandrel for each testing condition under the creep load ( $x$-axis: testing time in hours; $y$-axis: specimen displacement in $\mathrm{mm}$ ).

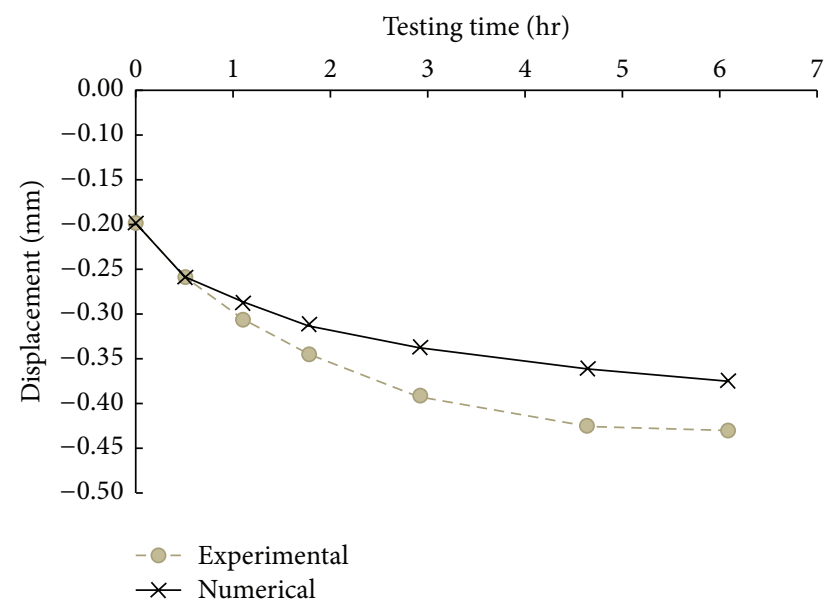

Figure 6: Example of the comparison between experimental and numerical results. Experimental dots represent the data extrapolated at the same time steps of the numerical predictions.

average behavior since in a number of comparisons the numerical data overestimate the experimental results while in other cases the predicted displacement underestimates the experimental one. The higher discrepancy with the increasing temperature was due to a premature failure of the specimen in the most critical conditions (i.e., $540^{\circ} \mathrm{C}-800 \mathrm{MPa}, 580^{\circ} \mathrm{C}$ $600 \mathrm{MPa}$, and $580^{\circ} \mathrm{C}-800 \mathrm{MPa}$ ) that were not included in the calibration phase of the coefficients. As declared in the Introduction, the procedure is able to account for yielding phenomena while damaging (material discontinuities) ones are neglected.

The overall discrepancies can be considered acceptable also accounting for possible small experimental uncertainties. In Figure 7, the results for the different tested levels of stress and temperature for the pure fatigue loading are reported. As for the creep tests, the testing configurations that led to a premature failure of the specimen during trials were not included in the calibration step $\left(540^{\circ} \mathrm{C}-800 \mathrm{MPa}\right.$ and $\left.580^{\circ} \mathrm{C}-800 \mathrm{MPa}\right)$. The average percentage error was higher than that for creep test and equal to $32.5 \%(0.124 \mathrm{~mm})$. As can be observed in Figure 7, the greatest experimental-numerical discrepancies are observed at highest temperature of $580^{\circ} \mathrm{C}$ that, for the specific investigated steel, coincides with the tempering temperature thus leading to a fast deterioration of the mechanical properties not accounted for in the model. However, process parameters are usually set in order to avoid this level of temperatures in the tools or, at least, to get it in limited portions of the material far from the yielding regions. In addition, at these conditions, damage in the form of material discontinuities (cracks, pores, and voids) reasonably appears and it is not modelled by the set of equations. This made also the average error of $32.5 \%$ acceptable.

A similar agreement between experimental and numerical results as that found for the creep tests was determined in case of creep-fatigue loading condition with an average percentage error of $14.3 \%$ all over the testing configurations corresponding to $0.08 \mathrm{~mm}$ (Figure 8).

As expected, the peak percentage error was, in each case, found for the combination higher temperature-higher stress level. 

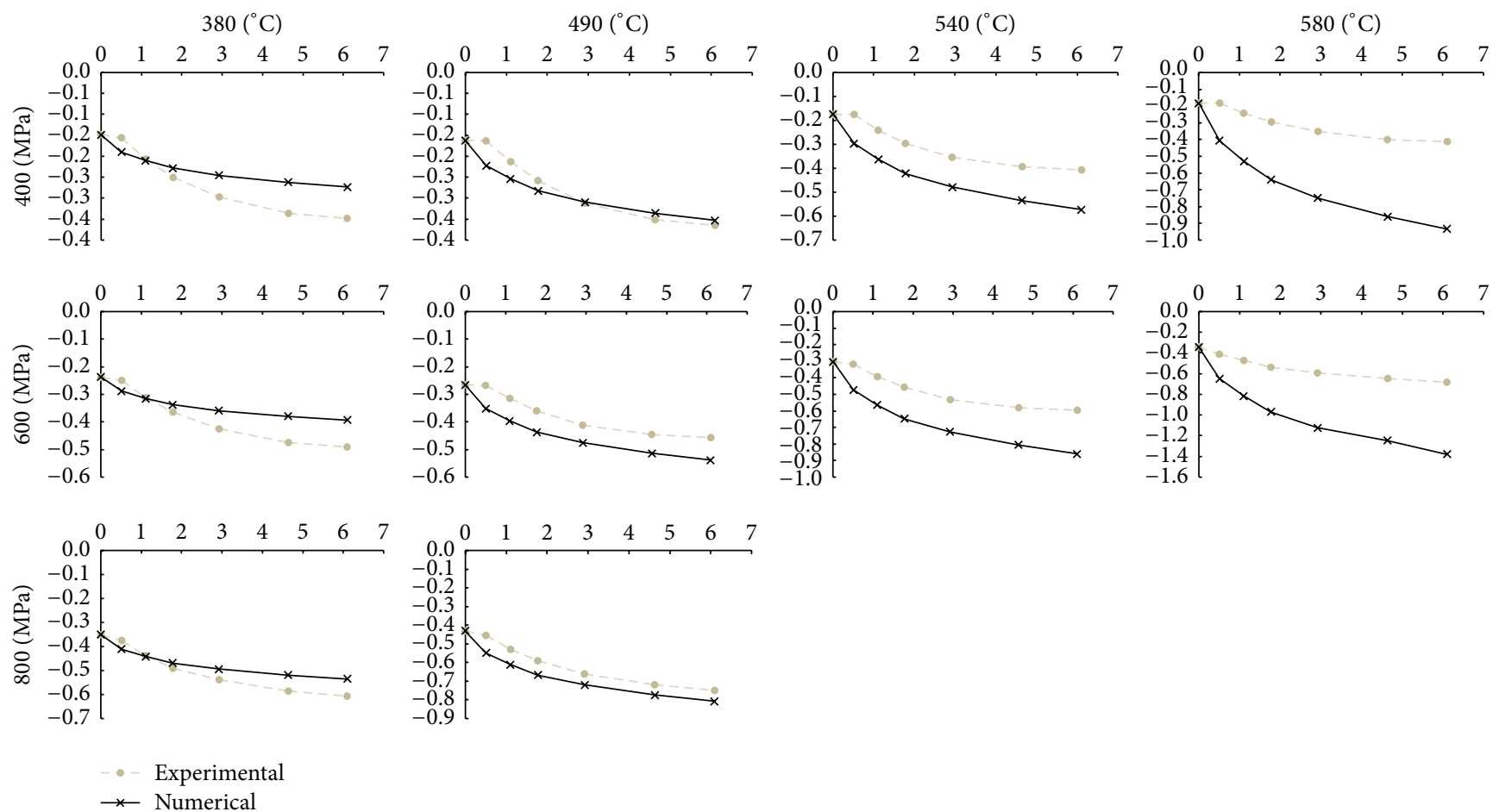

Figure 7: Experimental versus numerical displacement of the mandrel for each testing condition under the fatigue load ( $x$-axis: testing time in hours; $y$-axis: specimen displacement in $\mathrm{mm}$ ).
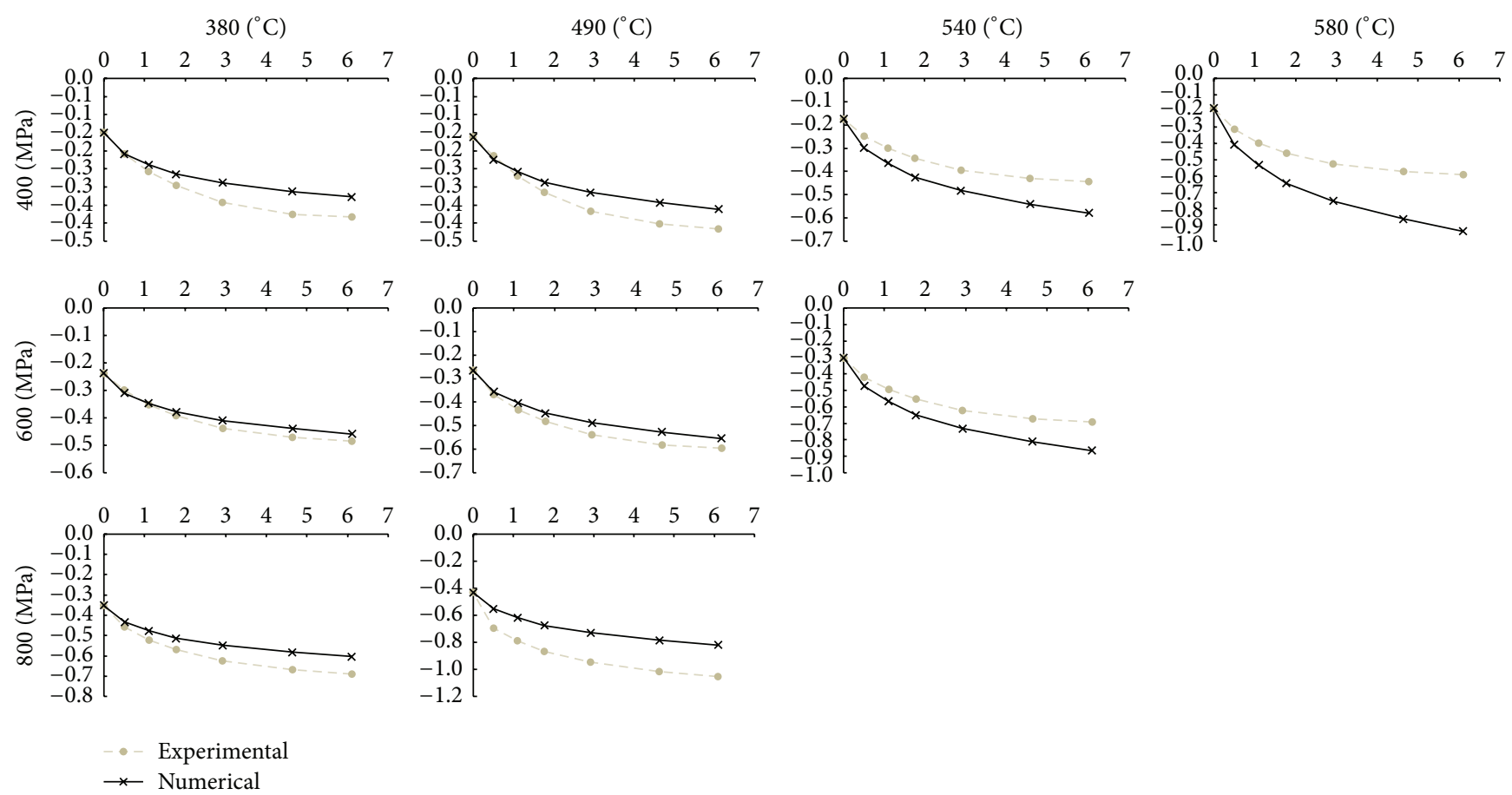

FIGURE 8: Experimental versus numerical displacement of the mandrel for each testing condition under the creep-fatigue load ( $x$-axis: testing time in hours; $y$-axis: specimen displacement in $\mathrm{mm}$ ). 


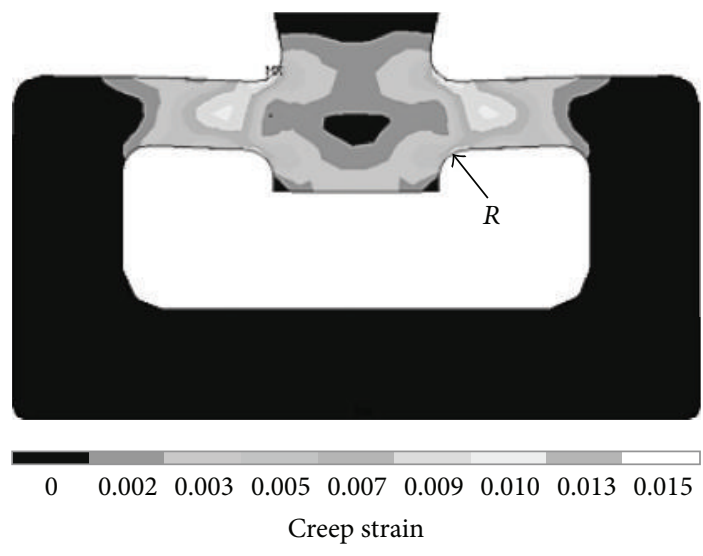

(a)

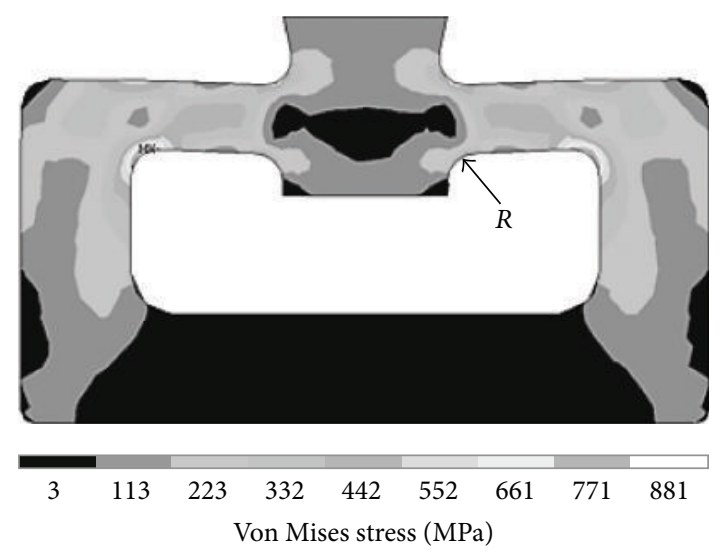

(b)

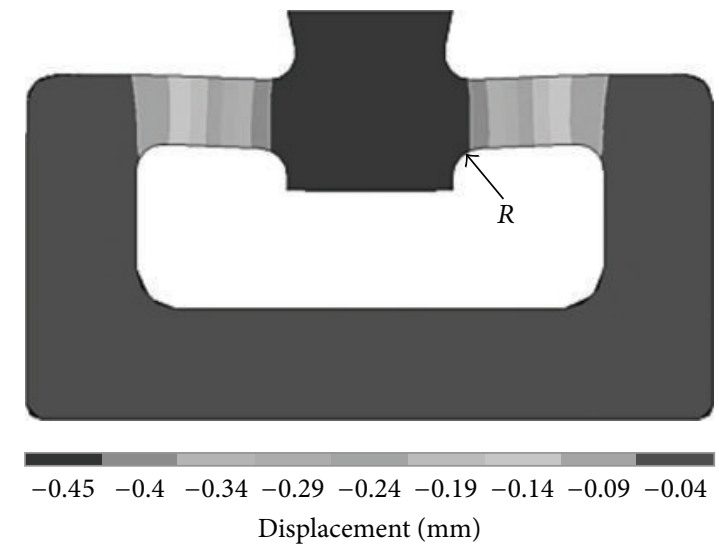

(c)

Figure 9: (a) Equivalent creep strain for the testing condition of $490^{\circ} \mathrm{C}$ and $400 \mathrm{MPa}$, (b) Von Mises stress distribution, and (c) displacement along the load direction.

In Figure 9, as example, some output results of the FE simulation performed according to the developed procedure at $490^{\circ} \mathrm{C}$ temperature and $400 \mathrm{MPa}$ as stress level in the legs are reported. Specimen is shown in the deformed final configuration after 6.1 hours. The peak equivalent creep strain (Figure $9(\mathrm{a})$ ) was found in the region of the connecting radius where both the highest temperature and stress level were located.

3.1. Verification against Specimens. The comparison between experimental and numerical results was made for two different geometries of the specimen not included in the calibration phase of the coefficients. Specimens differed for the values of the mandrel-legs connecting radius ( $R$, Figure 9$)$ : the values of $2 \mathrm{~mm}$ used for the calibration phase and $1 \mathrm{~mm}(R 1)$ and $3 \mathrm{~mm}(R 3)$ used for the verification one. A reduced experimental plan was investigated for the $R 1$ and $R 3$ configurations both tested at two stress levels, 400 and $800 \mathrm{MPa}$, but at fixed temperature $\left(540^{\circ} \mathrm{C}\right)$ and dwell time ( 3 minutes). Results are reported in Figure 10. The effect of the characteristic radius on the output results was significant, especially at the highest stress level $(800 \mathrm{MPa})$ : the $R 3$ configuration ended the test without premature failure while the $R 1$ configuration, with a sharper radius, failed after only two cycles.
For the lowest stress level $(400 \mathrm{MPa})$, the effect of the notch radius was less significant and for both the $R 3$ and the $R 1$ specimens the test was completed ( 6.1 hours). A good average agreement was found for these specimen geometries between experimental and numerical results. Average percentage error was less than $13 \%$ with a peak value of $28.4 \%$ for the $R 3$ configuration at the last cycle of the test performed at $800 \mathrm{MPa}$. The errors for the $R 1$ configuration tested at $400 \mathrm{MPa}$ were of the same order of magnitude while, at $800 \mathrm{MPa}$, data are not reported due to premature failure of the specimen after a reduced number of cycles.

3.2. Verification against an Industrial Extrusion Die. As last step of the work, the proposed procedure was applied to an industrial extrusion die whose process data were monitored and acquired during a controlled extrusion. The selected die had a standard geometry with a three-leg mandrel, equispaced at $120^{\circ}$, commonly adopted in industry to produce round tubes. The specific extruded hollow profile was a $5 \mathrm{~mm}$ thick tube with a $60 \mathrm{~mm}$ outer diameter (Figure 11).

The die was made of H11 steel. After 64 extrusion cycles (billets), the die was discarded due to an excessive permanent mandrel deflection equal to $0.32 \mathrm{~mm}$. This value was recorded by a feeler gauge after the die was dismounted from the 
$R 3$

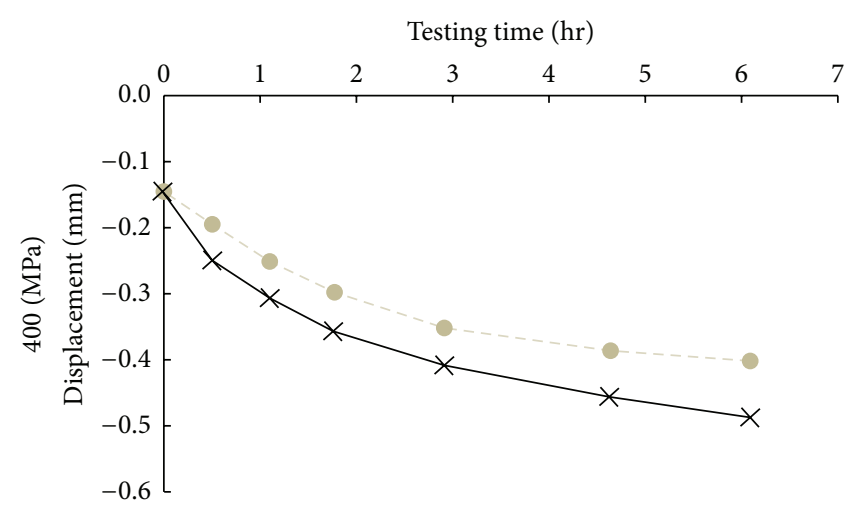

$R 1$

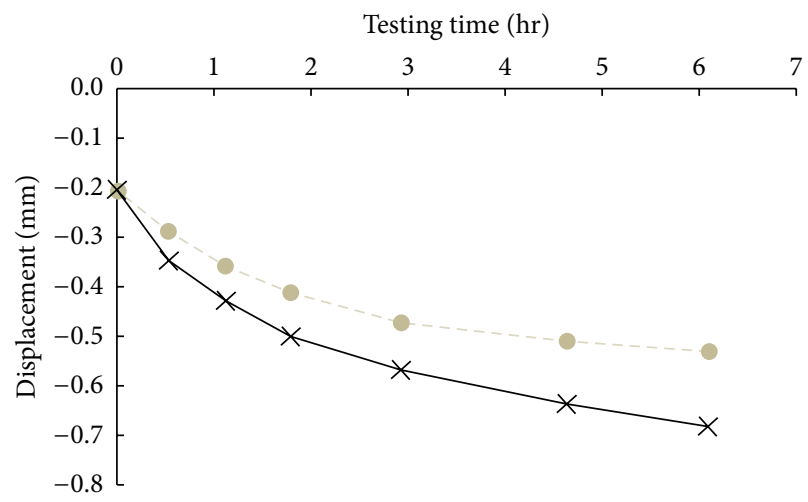

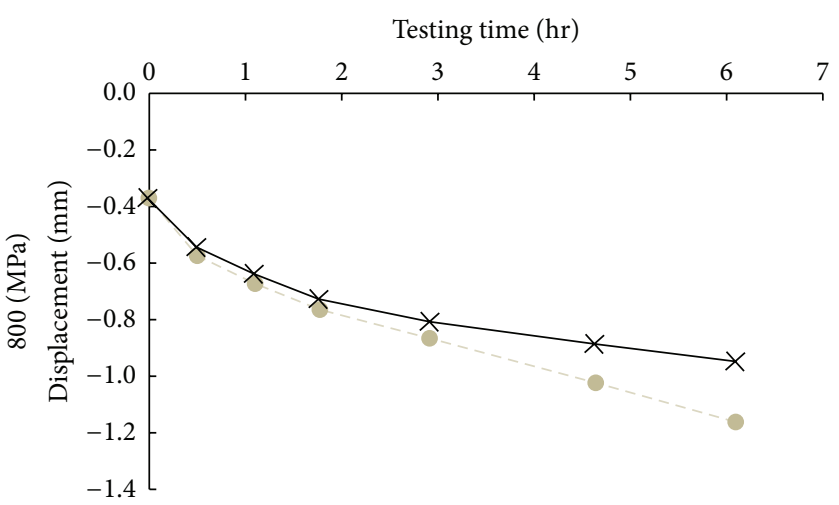

FIGURE 10: Experimental versus numerical mandrel peak displacement over the testing time for the test performed at $540^{\circ} \mathrm{C}$ and $400 \mathrm{MPa}$ for the $R 1$ and $R 3$ specimen configurations.

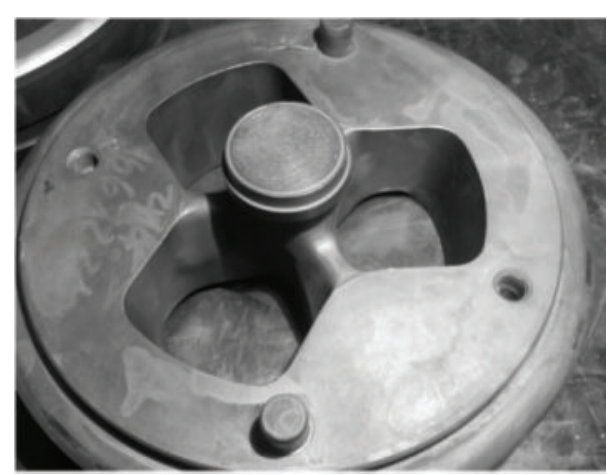

FIGURE 11: Mandrel of the porthole die used in the experiment.

press. In order to predict the pressure map on the die faces, a steady-state process simulation was performed by means of the FE code Altair HyperXtrude ${ }^{\circledR}$ (HX) [27] and by imposing boundary conditions, in terms of friction and heat exchange coefficients, previously verified [28-30]. With the aim of verifying the robustness of code computations, experimental and numerical results were compared in terms of extrusion load, profiles exit velocity, and die and profile temperatures. A good agreement was found with percentage errors less than $5 \%$ for each prediction (Table 4 ).

An FE model of the die was then generated in a different FE code specifically dedicated to structural analyses (ANSYS
TABLE 4: Experimental versus numerical predictions for the industrial extrusion die.

\begin{tabular}{lccc}
\hline & Experimental & Numerical & \% error \\
\hline Peak extrusion load [tons] & 3158 & 3290 & 4.1 \\
Exit velocity $[\mathrm{mm} / \mathrm{s}]$ & 121 & 115 & 4.9 \\
Die temperature $\left[{ }^{\circ} \mathrm{C}\right]$ & 423 & 440 & 4.0 \\
Profile exit temperature $\left[{ }^{\circ} \mathrm{C}\right]$ & 560 & 564 & 0.7 \\
\hline
\end{tabular}

V17.0 Inc.) in which the subroutines for (8) were defined in the APDL language and then implemented. A single solid was generated including die and mandrel thus avoiding contact generation and then significantly reducing the computational time. However, this did not alter the output results due to the rigid die-mandrel constraints as made with reference pins (Figure 11). The aluminum pressure map applied to the die faces in contact with the billet was imported from the process simulation code (peak value $340 \mathrm{MPa}$ ) as well as the temperature distribution (Figure 12(a)). Displacement constraints were applied accounting for experimental settings: the die faces in contact with the bolster were fixed in the extrusion direction while the nodes in contact with the saddle load on the press were fixed in the other directions. From the experiment, an extrusion time of 300 seconds was computed and imposed as dwell time for the subroutine calculations in the FE simulation (Figure 12(b)). The total simulation 


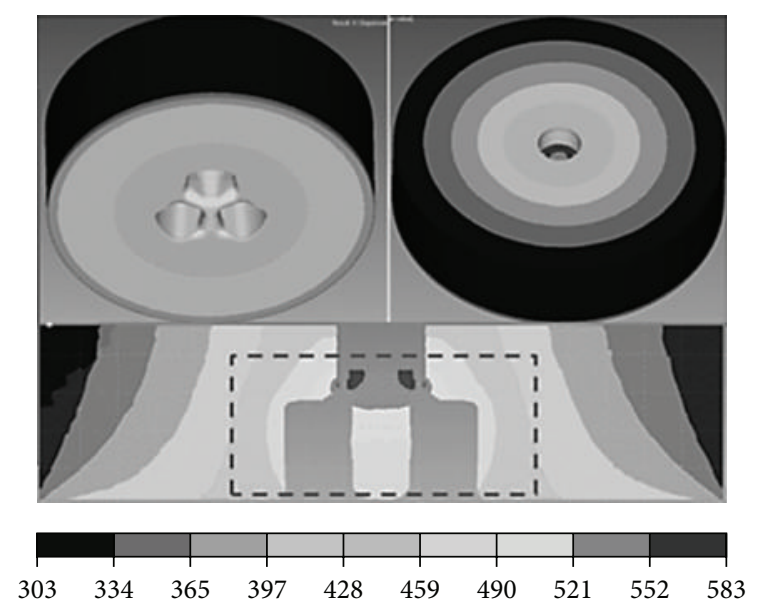

(a)

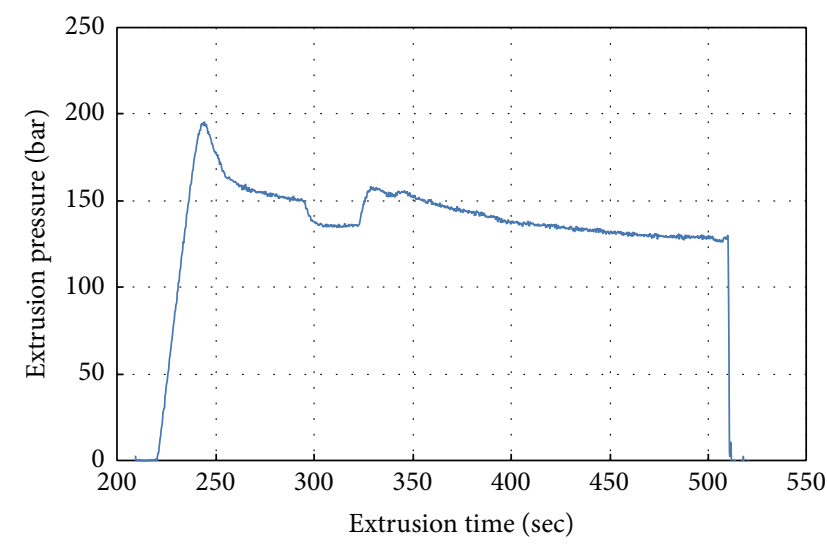

(b)

FIGURE 12: (a) Temperature distribution $\left[{ }^{\circ} \mathrm{C}\right]$ in the die as output from the process simulation. Within the dashed area is the yielding region. (b) Experimental pressure-time diagram for a single extrusion.

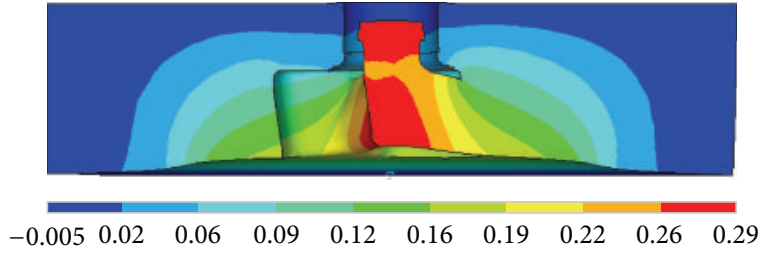

(a)

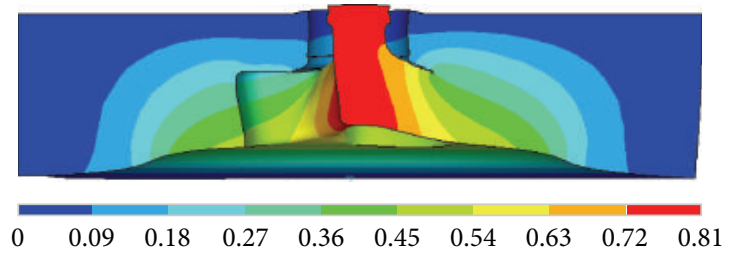

(b)

FIGURE 13: Die deflection [mm] along the extrusion direction as predicted with a static analysis (a) and according to the proposed procedure (b).

time was fixed to 16.6 hours, corresponding to around 200 extrusion cycles, even if experimentally the die failed after 64 billets.

The standard industrial calculations used as bases for die design decisions are usually static structural analyses equivalent to a single forming cycle. In order to compare the level of accuracy of such type of calculations with those performed by means of more sophisticated computations like those offered by the proposed procedure, the output mandrel deflection of the die was computed after one cycle (static) and after 200 extrusion cycles, a reasonable number for a standard extrusion die life. As showed in Figure 13, the mandrel deflection was $0.28 \mathrm{~mm}$ in loaded condition for the static computation (a) while it was $0.81 \mathrm{~mm}$ for the multicycle simulation (b) as got by applying the procedure. Thus, it is interesting to note that if $0.28 \mathrm{~mm}$ is used as value to estimate the die lifetime after 200 working cycles, an error up to $64 \%$ is committed.

More in detail, Figure 14 shows the trend of the mandrel displacement with increasing the number of extruded billets as computed by means of the developed procedure. As previously stated, while after a single billet (static load) the mandrel was displaced by $0.28 \mathrm{~mm}$ under loading, after 55 billets the total deflection was increased to $0.65 \mathrm{~mm}$ reaching a value $0.81 \mathrm{~mm}$ after 200 billets. So, this type of information can be successfully used to define the number of workable components in order to remain within the required tolerances. If, for example, it is experimentally tested or estimated from practical experience that the maximum experimental allowed die displacement is $0.5 \mathrm{~mm}$, from the computation it emerges that a maximum of 12 billets can be consecutively extruded with the selected set of process parameters and die design.

Concerning the comparison with the experimental measurement after 64 billets ( $0.32 \mathrm{~mm}$ in unloaded condition), the numerical procedure predicted a mandrel deflection of $0.67 \mathrm{~mm}$ that was purged of the elastic quote of $0.28 \mathrm{~mm}$ achieved in the first cycle and equalled $0.39 \mathrm{~mm}$. A good agreement was then achieved between experimental and numerical prediction with an absolute error less than $0.1 \mathrm{~mm}$ $(0.07 \mathrm{~mm})$.

\section{Conclusions}

In the present work, a novel modelling approach is presented for the prediction of the time-dependent deformation undergone by hot forming tools in the creep-fatigue regime. Novel regression equations were developed to express the dependencies of the coefficients on the stress-temperature state in each point and on the dwell-time value representing the workpiece-tool contact time typical of the specific application. The extrusion context and the H11 (X38CrMV-5) tool 


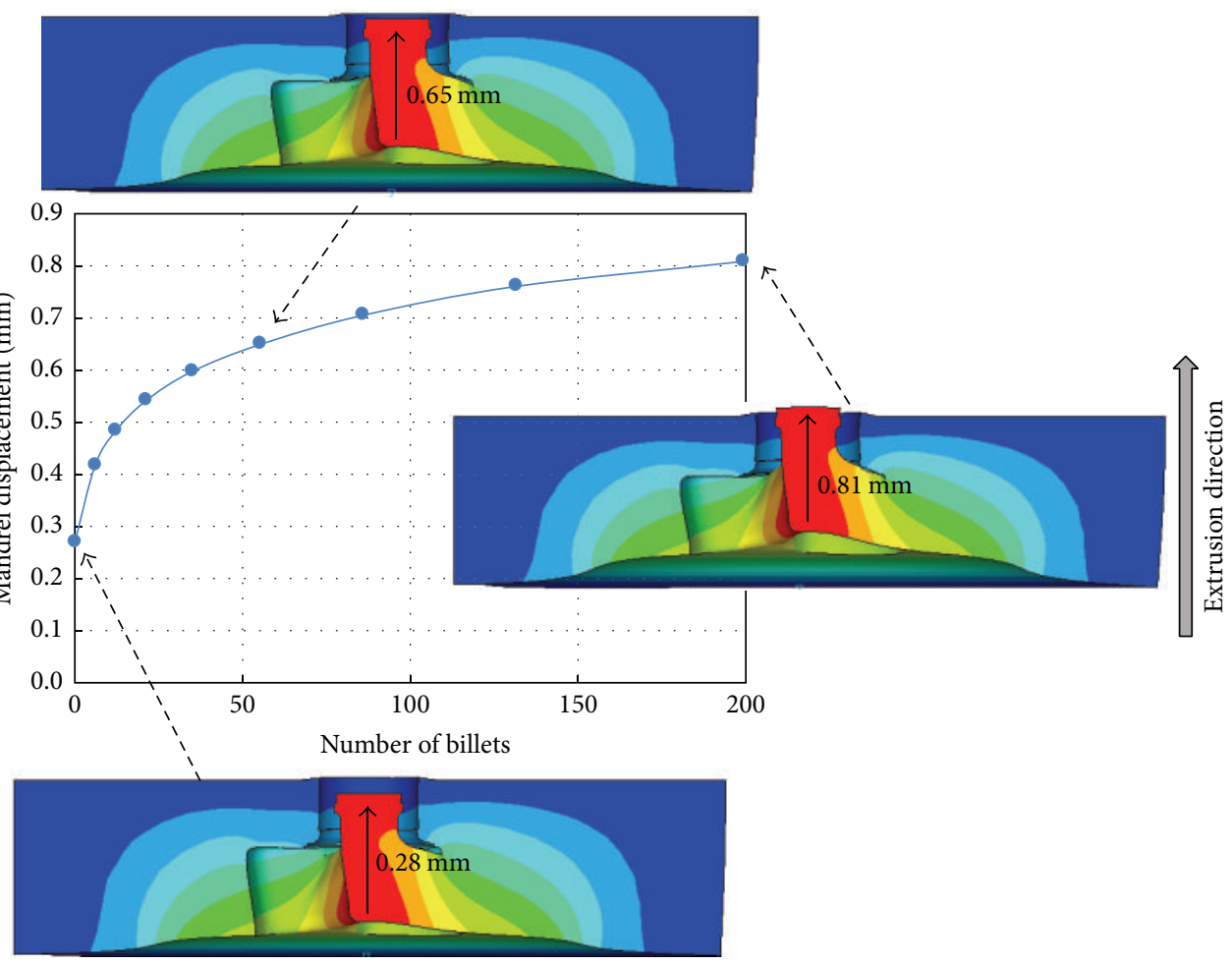

FIGURE 14: Total mandrel displacement [mm] against number of consecutively extruded billets as computed by the proposed model. Three plots of the FE simulation of the mandrel are reported as example.

steel were selected as examples to describe and validate the procedure; however, it is of general applicability to different forming tools and to a variety of tool materials.

Physical experiments performed at different levels of stress and temperature and under three loading types (creep, fatigue, and creep-fatigue) were used to calibrate the coefficients of the novel equations. Comparison of numerical predictions with experimental data showed a good agreement for creep and creep-fatigue conditions with average errors of $12.7 \%(0.06 \mathrm{~mm})$ and $14.3 \%(0.08 \mathrm{~mm})$, respectively. The pure fatigue condition was less well fitted showing an average error of $32.5 \%$. However, in each tested condition, the greater experimental-numerical discrepancies were found for the most critical conditions, that is, higher stress and temperature levels in which damage (material discontinuities) reasonably appeared.

Then, two additional specimen configurations were used as experimental data to be compared with numerical predictions. For three of the four tested conditions under creepfatigue load and $540^{\circ} \mathrm{C}$, the average percentage error was less than $13 \%$. The configuration with a sharper radius failed after only two cycles at the higher stress level $(800 \mathrm{MPa})$, so that comparison with numerical data was not feasible.

In the last part of the work, a verification was performed on an industrial extrusion die. A very good agreement in terms of permanent displacement after 64 consecutive cycles (billets) was achieved with an experimental value of 0.32 against 0.39 numerically predicted by the proposed set of equations.
This confirmed the capability of the novel approach to accurately account for the induced stress and temperature states as well as for the specific dwell time, characteristic of the set of process parameters and die design. The proposed procedure can be therefore regarded as a valid support for die designer in the "a priori" estimation of time-dependent deformation of hot forming tools working under the creepfatigue regime.

\section{Competing Interests}

The authors declare that they have no competing interests.

\section{References}

[1] J. Lemaitre and J. L. Chaboche, Mechanics of Solid Materials, Cambridge University Press, Cambridge, UK, 1990.

[2] R. Domagaoj, Lifetime Prediction and Constitutive Modeling for Creep-Fatigue Interaction, vol. 13 of Materialkundlich-Technische Reihe, Gebruder Borntraeger, Berlin, Germany, 1996.

[3] M. Deshpande, A. Groseclose, and T. Altan, "Selection of die materials and surface treatments for increasing die life in hot and warm forging," in Proceedings of the FIATECH Technology Conference \& Showcase, Paper no. 644-FIA, April 2011.

[4] R. Ebara and K. Kubota, "Failure analysis of hot forging dies for automotive components," Engineering Failure Analysis, vol. 15, no. 7, pp. 881-893, 2008.

[5] B. K. Kosec, L. Kosec, and J. Kopač, "Analysis of casting die failures," Engineering Failure Analysis, vol. 8, no. 4, pp. 355-359, 2001. 
[6] A. F. M. Arif, A. K. Sheikh, S. Z. Qamar, and K. M. Al-Fuhaid, "Modes of die failure and tool complexity in hot extrusion of Al-6063," in Proceedings of the 16th International Conference on Production Research (ICPR '01), Prague, Czech Republic, 2001.

[7] A. F. M. Arif, A. K. Sheikh, and S. Z. Qamar, "A study of die failure mechanisms in aluminum extrusion," Journal of Materials Processing Technology, vol. 134, no. 3, pp. 318-328, 2003.

[8] A. K. Sheikh, A. F. M. Arif, and S. Z. Qamar, "A probabilistic study of failures of solid and hollow dies in hot aluminum extrusion," Journal of Materials Processing Technology, vol. 155-156, no. 1-3, pp. 1740-1748, 2004.

[9] A. Kocanda, "Die deformation and geometry of extruded components," in Proceedings of the 2nd International Conference on Industrial Tools (ICIT '99), pp. 69-78, Rogaška Slatina, Slovenia, April 1999.

[10] M. M. Kostic and L. G. Reifschneider, "Design of extrusion dies," in Encyclopedia of Chemical Processing, S. Lee, Ed., pp. 633-649, CRC Press, New York, NY, USA, 2007.

[11] T. Pinter and B. Reggiani, "Quantitative evaluation of porthole dies design practices by means of FE analyses," in Proceedings of the Aluminum Two Thousand 8th World Congress, Milan, Italy, May 2013.

[12] D. Pietzka, N. B. Khalifa, L. Donati, L. Tomesani, and A. E. Tekkaya, "Extrusion benchmark 2009 experimental analysis of deflection in extrusion dies," Key Engineering Materials, vol. 424, pp. 19-26, 2010.

[13] B. Reggiani, L. Donati, and L. Tomesani, "Evaluation of different FE simulation codes in the stress analysis of extrusion dies," International Journal of Material Forming, vol. 3, no. 1, pp. 395398, 2010

[14] Z. Ahmer, V. Velay, G. Bernhart, and F. Rézaï-Aria, "Cyclic behaviour simulation of X38CRMOV5-47HRC (AISI H11)tempered martensitic hot-work tool steel," International Journal of Microstructure and Materials Properties, vol. 3, no. 2-3, pp. 326-335, 2008.

[15] S. T. Wang, R. S. Lee, H. Y. Li, and C. H. Chen, "Optimal die design for three-dimensional porthole extrusion using the Taguchi method," Proceedings of the Institution of Mechanical Engineers, Part B: Journal of Engineering Manufacture, vol. 220, no. 6, pp. 1005-1009, 2006.

[16] V. Velay, G. Bernhart, D. Delagnes, and L. Penazzi, "A continuum damage model applied to high-temperature fatigue lifetime prediction of a martensitic tool steel," Fatigue and Fracture of Engineering Materials and Structures, vol. 28, no. 11, pp. 1009-1023, 2005.

[17] C. Sommitsch, R. Sievert, T. Wlanis, B. Günther, and V. Wieser, "Modelling of creep-fatigue in containers during aluminium and copper extrusion," Computational Materials Science, vol. 39, no. 1, pp. 55-64, 2007.

[18] J. L. Chaboche, "Constitutive equations for cyclic plasticity and cyclic viscoplasticity," International Journal of Plasticity, vol. 5, no. 3, pp. 247-302, 1989.

[19] J. L. Chaboche, "On some modifications of kinematic hardening to improve the description of ratchetting effects," International Journal of Plasticity, vol. 7, no. 7, pp. 661-678, 1991.

[20] V. Velay, G. Bernhart, and L. Penazzi, "Cyclic behavior modeling of a tempered martensitic hot work tool steel," International Journal of Plasticity, vol. 22, no. 3, pp. 459-496, 2006.

[21] B. Reggiani, L. Donati, J. Zhou, and L. Tomesani, "The role of creep and fatigue in determining the high-temperature behaviour of AISI H11 tempered steel for aluminium extrusion dies," Journal of Materials Processing Technology, vol. 210, no. 12, pp. 1613-1623, 2010.

[22] V. Velay, D. Delagnes, and G. Bernhart, "Advances in cyclic behavior and lifetime modeling of tempered martensitic steels based on microstructural considerations," Key Engineering Materials, vol. 378-379, pp. 81-100, 2008.

[23] R. K. Penny and D. L. Marriott, Design for Creep, McGraw-Hill, Maidenhead, UK, 1971.

[24] H. Berns, C. Broeckmann, and H. F. Hinz, "Creep of high speed steels part I-experimental investigations," in Proceedings of the the 6th International Tooling Conference, pp. 325-337, Karlstad University, Karlstad, Sweden, September 2002

[25] H. Berns and F. Pschenitzka, "Das Kriechverhalten von Warmarbeitsstählen mit 5\% Chrom," Materialwissenschaft und Werkstofftechnik, vol. 11, no. 7, pp. 258-264, 1980.

[26] B. Reggiani, L. Donati, and L. Tomesani, "Thermal-electric simulations for the temperature settings in a creep-fatigue test," in Proceedings of the 27th Danubia Adria Symposium, Wrocław, Poland, September 2010.

[27] HyperXtrude (version 12.0), Simulation software for Extrusion Process, Altair Engineering Inc, USA, http://www.altairhyperworks.com.

[28] B. Reggiani, A. Segatori, L. Donati, and L. Tomesani, "Prediction of charge welds in hollow profiles extrusion by FEM simulations and experimental validation," International Journal of Advanced Manufacturing Technology, vol. 69, no. 5-8, pp. 1855-1872, 2013.

[29] C. Zhang, G. Zhao, Z. Chen, H. Chen, and F. Kou, "Effect of extrusion stem speed on extrusion process for a hollow aluminum profile," Materials Science and Engineering B: Solid-State Materials for Advanced Technology, vol. 177, no. 19, pp. 1691-1697, 2012.

[30] M. Reddy and L. Mazzoni, "Benchmark results," in Proceedings of the 2nd International Conference on Extrusion and Benchmark, pp. 99-102, Bologna, Italy, September 2007. 

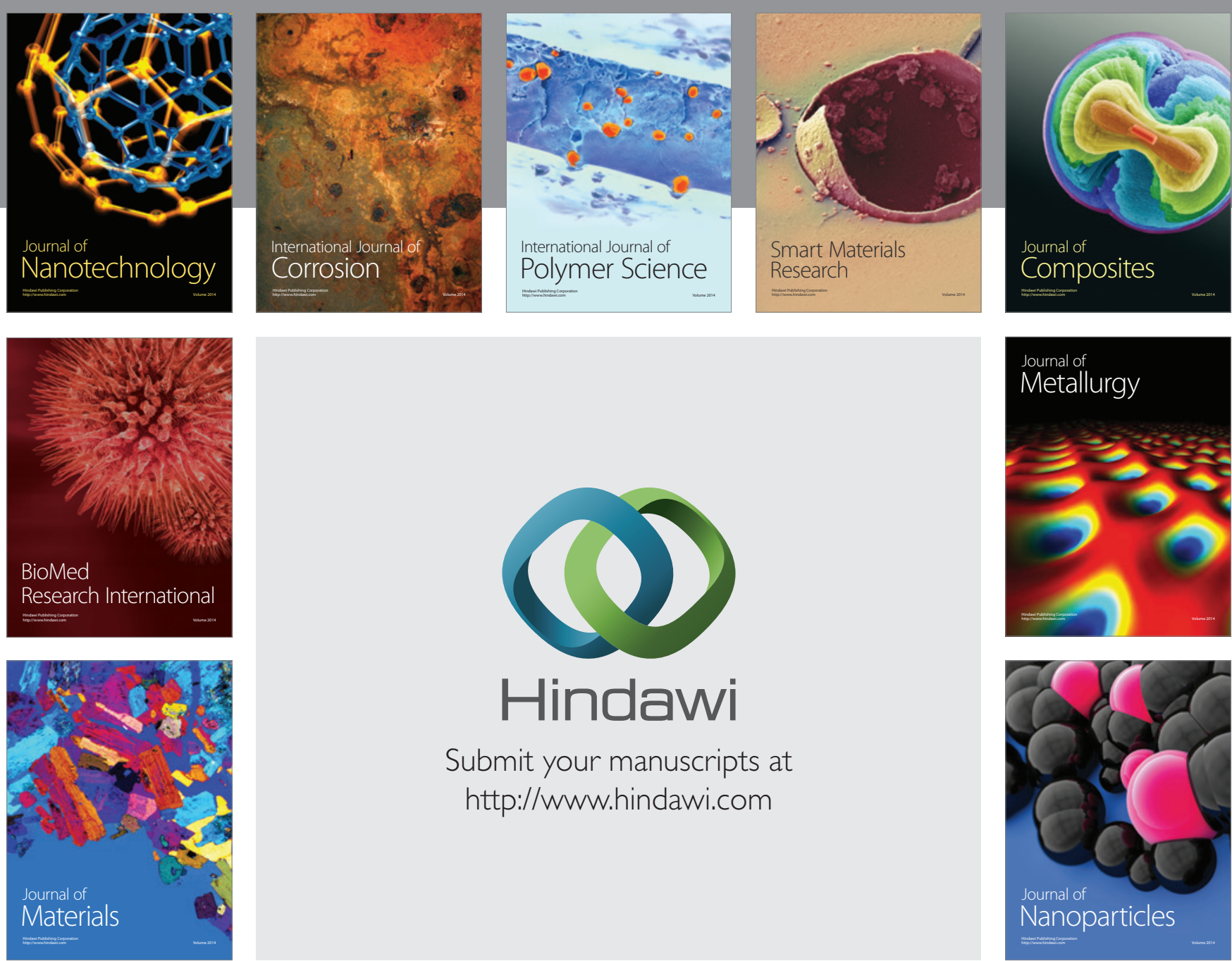

\section{Hindawi}

Submit your manuscripts at

http://www.hindawi.com

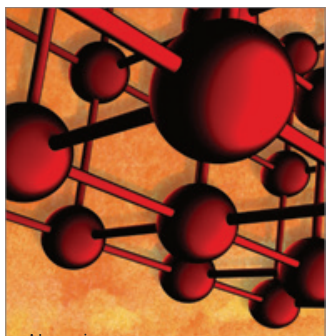

Materials Science and Engineering
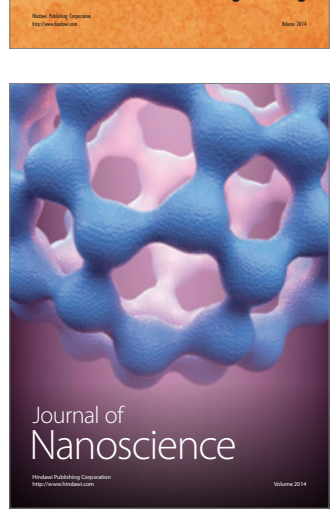
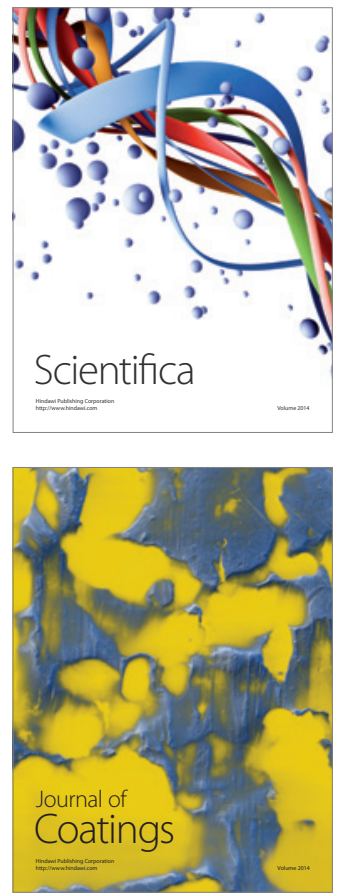
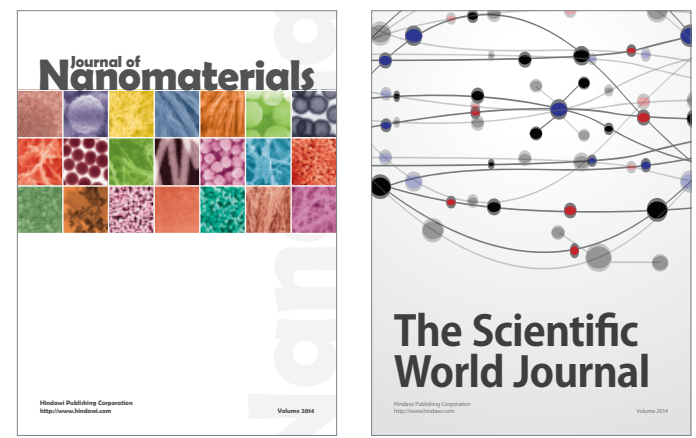

The Scientific World Journal
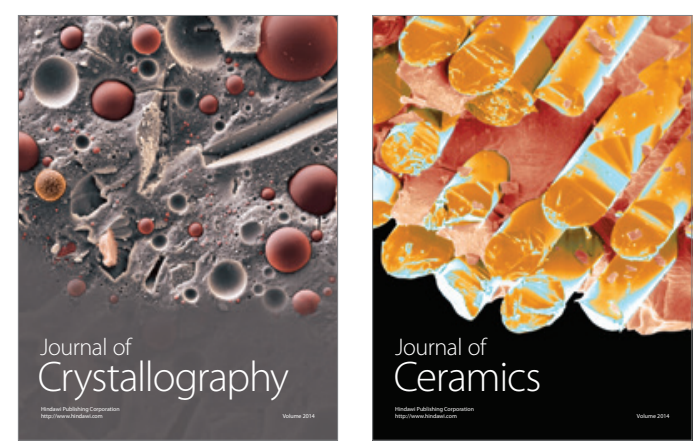
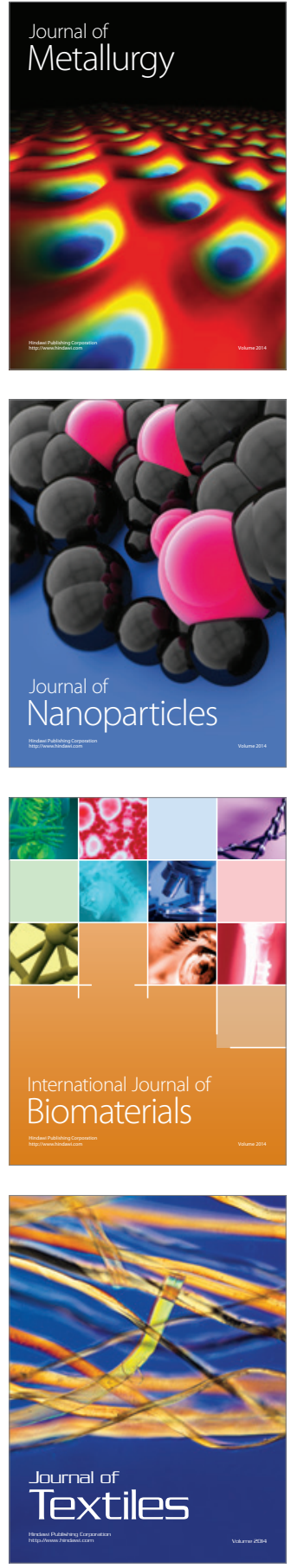